УДК 616.33-008.17-06:616.2]-089:615.036.8

DOI 10.11603/2414-4533.2017.2.7718

( М. Р. ПАРАНЯК, Вікт. Вол. ГРУБНИК

Одеський національний медичний університет

\title{
Ефективність хірургічного лікування хворих із респіраторними проявами гастроезофагеальної рефлюксної хвороби
}

\begin{abstract}
Мета роботи: порівняння ефективності консервативної терапії та хірургічного лікування пацієнтів з респіраторними проявами гастроезофагеальної рефлюксної хвороби та грижами стравохідного отвору діафрагми.

Матеріали і методи. 41 пацієнту було виконано лапароскопічні фундоплікації за Ніссеном та 25 пацієнтам проведено консервативну терапію гастроезофагеальної рефлюксної хвороби. Результати лікування оцінено за допомогою цілодобового pH- моніторингу стравоходу та опитувальника якості життя GERD-HRQL. Також виконували визначення інтенсивності печії за шкалою Likert, інтенсивності нападу кашлю за даними 10-бальної візуальної аналогової шкали, кількісного показника нападів кашлю впродовж однієї доби, індексу симптому рефлюксного кашлю.

Результати досліджень та їх обговорення. Встановлено достовірно кращий результат $(\mathrm{p}<0,001)$ відносно зменшення частоти та інтенсивності кашлю у хворих, яким виконували лапароскопічні фундоплікації. Регрес типової симптоматики також був кращим (р < 0,001) у хворих, яким проводились хірургічні втручання.
\end{abstract}

Ключові слова: гастроезофагеальна рефлюксна хвороба; лапароскопічна фундоплікація; позастравохідні прояви; кашель.

Постановка проблеми і аналіз останніх досліджень і публікацій. Окрім типової симптоматики гастроезофагеальної рефлюксної хвороби (ГЕРХ) у вигляді печії, відрижки повітрям, відрижки кислим, дисфагії, нудоти, можливе виникнення позастравохідних проявів захворювання, найбільш поширеними серед яких є респіраторні [1]. За даними науковців [2], ГЕРХ є причиною хронічного кашлю у більш ніж 25 \% випадків. Виявлено збіг у часі гастроезофагеальних рефлюксів, за даними цілодобового езофагоpH-моніторингу, з нападами кашлю [3]. Виникнення кашлю зумовлене подразненням кашльових С-рецепторів, що розташовані в дихальних шляхах, плеврі, діафрагмі, перикарді та стравоході. Під час виникнення запального процесу в даних анатомічних структурах виділяються такі медіатори запалення, як простагландини, брадикінін, субстанція Р та ін., що стимулюють кашльові рецептори. Відомо два основні механізми виникнення кашлю, провокованого ГЕРХ:

1. Подразнення рефлюксантом рецепторів n.vagus дистальної частини стравоходу, що спричиняє виникнення езофаготрахеобронхіального рефлексу.

2. Мікро- та макроаспірація рефлюксанту, що призводить до подразнення рецепторів гортані і бронхів, та як наслідок - виникнення кашльового рефлексу [4].

Традиційно при лікуванні проявів гастроезофагеального рефлюксу використовують інгібітори протонної помпи (ІПП), проте їхня ефективність при позастравохідних проявах ГЕРХ $є$ достатньо сумнівною $[1,5]$. Було виявлено, що при наяв- ності у таких пацієнтів грижі стравохідного отвору діафрагми (ГСОД) симптоматика ГЕРХ є більш вираженою, також такі хворі гірше реагують на антирефлюксну консервативну терапію [6]. 3 літературних джерел [7] відомо, що розміри ГСОД суттєво впливають на тактику та результати лікування ГЕРХ, а питання вибору методу лікування пацієнтів із респіраторною симптоматикою ГЕРХ та великими і малими ГСОД остаточно не вирішене.

Мета роботи: порівняти ефективність консервативної терапії та хірургічного лікування пацієнтів із респіраторними проявами ГЕРХ та ГСОД.

Матеріали і методи. На базі відділень загальної хірургії та малоінвазивної хірургії Одеської ОКЛ за період з 2015 до 2016 р. нами було прооперовано 46 осіб, в тому числі 18 (39 \%) чоловіків та 28 (61 \%) жінок віком від 38 до 69 років 3 респіраторними проявами ГЕРХ (кашель, бронхіальна астма) та ГСОД.

Перед виконанням лікувальних заходів пацієнтам проводили такі обстеження, як:

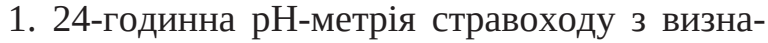
ченням індексу DeMeester.

2. Ендоскопічне обстеження стравоходу та шлунка.

3. Рентгенологічне обстеження стравоходу, шлунка та дванадцятипалої кишки.

4. Спірографія.

5. Оцінка інтенсивності печії за шкалою Likert, де 1 бал - скарги відсутні, 2 - слабка інтенсивність печії, 3 - помірна, 4 - сильна, 5 - нестерпна.

6. Оцінка інтенсивності нападів кашлю за даними 10-бальної візуальної аналогової шкали 
(ВАШ). Де 0 балів - кашель не турбує, 5 балів кашель середньої інтенсивності, 10 балів - напад кашлю нестерпний.

7. Оцінка кількісного показника нападів кашлю впродовж однієї доби.

8. Опитувальника якості життя GERD-HRQL [9].

9. Визначення індексу симптому рефлексного кашлю. Обраховували (у відсотках) відношення кількості нападів кашлю під час гастроезофагеальних рефлюксів до загальної кількості нападів кашлю [8].

10. Консультації пульмонолога, гастроентеролога.

Після виключення із дослідження пацієнтів 3 бронхіальною астмою тяжкого та вкрай тяжкого ступенів тяжкості, тяжкою супутньою патологією ASA III було сформовано дослідну групу. Даним пацієнтам виконувались лапароскопічні фундоплікації за методикою Ніссена 3 пластикою ГСОД. Залежно від величини розмірів ГСОД, а саме у випадку грижового дефекту площею $<10$ см$^{2}$ (малі грижі), виконували крурорафію, при розмі-

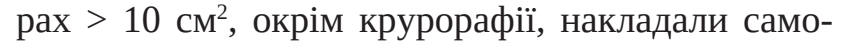
фіксуючу сітку Progrip. Причина використовування вказаного типу сіток описана у нашому попередньому дослідженні, про переваги використання самофіксуючих сіток Progrip відносно звичайних поліпропіленових сіток, в хірургічному лікуванні хворих з великими ГСОД [10].

До першої групи було включено 41 пацієнта, в тому числі 13 (32 \%) чоловіків та 28 (68 \%) жінок віком від 42 до 64 років.

До другої (контрольної групи) було відібрано 25 пацієнтів, в тому числі 12 (48 \%) чоловіків та 13 (52 \%) жінок віком від 39 до 69 років, яким проводили консервативну терапію ГЕРХ. Схема консервативного лікування включала: мотіліум 10 мг по 1 таблиці 3 рази на добу перед прийманнями їжі + рабепразол 20 мг 1 раз на добу зранку, впродовж 12 тижнів. При потребі пацієнти самостійно продовжували приймання даних препаратів. Медикаментозне лікування ГЕРХ пацієнтам другої групи проводилась в амбулаторних умовах.

Віддалені результати лікування оцінено через 6 та 12 місяців. Статистичну достовірність оцінювали за допомогою одностороннього $t$-критерію Student. Розрахунки виконувались у середовищі табличного процесора MSExcel.

Результати досліджень та їх обговорення. У хворих першої групи середня тривалість операційного втручання становила $(80,5 \pm 11)$ хвилин. Ускладнень під час операційних втручань не було. Інтраопераційно нами було виявлено, що у 18 осіб розмі- ри грижового дефекту становили $>10 \mathrm{~cm}^{2}$, що стало причиною використання сітчатого імплантату.

В одного пацієнта на момент огляду через 12 місяців виявлено рецидив ГСОД. Цікавим був факт, що рецидив грижі виник у пацієнта з малими розмірами грижового дефекту, якому під час операції не встановлювали самофіксуючу сітку Progrip. Незважаючи на це, хворий відмовився від виконання повторного операційного втручання, в зв'язку з відсутністю скарг на печію. Характеристика респіраторних проявів ГЕРХ у пацієнтів дослідної і контрольної груп на момент звернення за медичною допомогою та віддалені результати їхнього лікування відображена на рисунку 1.

Під час повторних оглядів через 6 місяців у хворих першої групи скарги на кашель регресували, або були мінімальними (рис. 2). Періодично виникали покашлювання, що було розцінено пацієнтами, як 1-2 бали інтенсивності кашлю за ВАШ. Через 12 місяців після проведених лікувальних заходів у пацієнтів групи хірургічного лікування скарги не посилювались. 21 (84 \%) хворий другої групи вказував на повний регрес або мінімізацію даних скарг, у чотирьох хворих (16 \%) скарги були незмінними. Варто зауважити, що через 12 місяців у хворих, яким не виконували операції, виникло загальне погіршення респіраторної симптоматики, зросла середня частота нападів кашлю та його інтенсивність.

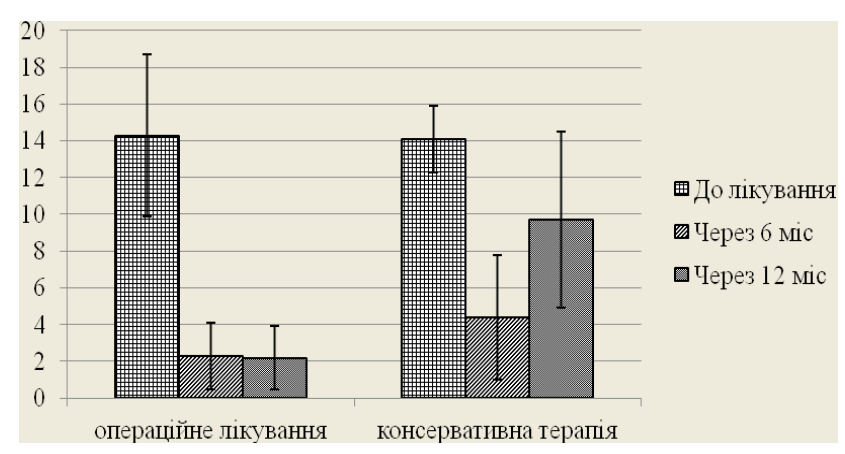

Рис. 1. Кількість нападів кашлю у хворих дослідної та контрольної груп на момент оглядів.

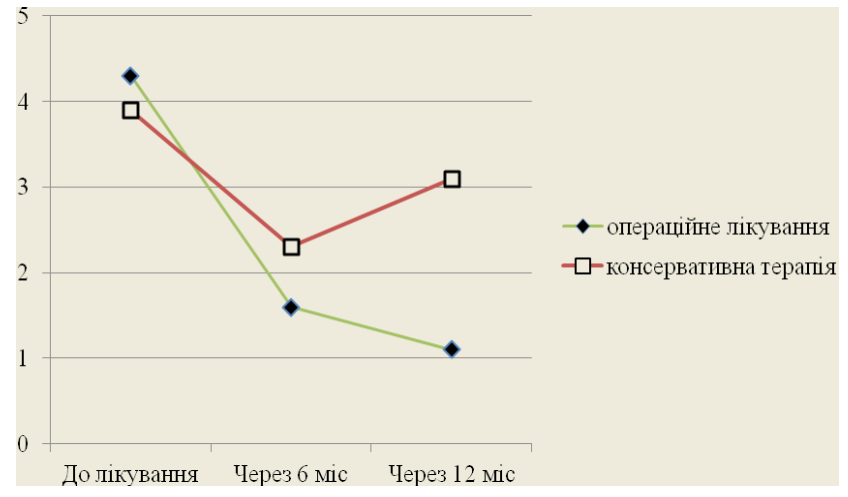

Рис. 2. Інтенсивність кашлю за ВАШ у хворих дослідної та контрольної груп на момент оглядів. 
Після статистичних підрахунків виявлено, що проведені лікувальні заходи у пацієнтів першої групи виявились високоефективними, привели до достовірного зменшення частоти нападів кашлю $\mathrm{i}$ його інтенсивності як через 6 місяців $(\mathrm{p}<0,0001)$, так і через 12 місяців (р <0,0001) після лікування. Зниження показника середньої кількості нападів кашлю та інтенсивності кашлю за ВАШ у другій групі хворих було також достовірно значущим як через 6 місяців ( $<0,0001)$, так і через 12 місяців (р <0,0001).

Перед початком лікування хворі першої і другої груп статистично не відрізнялись за показниками кількості нападів кашлю та його інтенсивності, середнім значенням індексу DeMeester. Різниця індексу симптомів рефлексного кашлю з високою ймовірністю $(\mathrm{p}=0,1424)$ також була випадковою, іншими словами, показники груп не відрізнялись значно. Під час порівняння результатів лікування в дослідній та контрольній групах (табл. 1) виявлено, що у хворих, яким виконували лапароскопічні фундоплікації, респіраторна симптоматика регресувала більш суттєво, також нижчими були індекс DeMeester та індекс симптому рефлюксного кашлю.

Під час звернення за медичною допомогою 33 (80,4 \%) пацієнти першої групи та 21(84 \%) пацієнт другої групи скаржились на періодично виникаючу печію. Після проведеного лікування інтенсивність печії за Likert у першій групі хворих

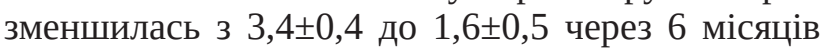
$(\mathrm{P}<0,001)$ та $1,5 \pm 0,4$ через 12 місяців $(\mathrm{P}<0,001)$. У другій групі також спостерігався регрес вира-

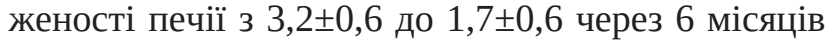
$(\mathrm{P}<0,001)$ та 2,4 $\pm 0,3$ через 12 місяців $(\mathrm{P}<0,001)$.

Якість життя згідно з опитувальником GERDHRQL у пацієнтів, яким виконували лапароско-

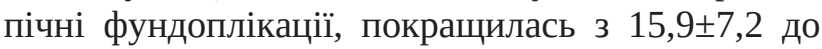

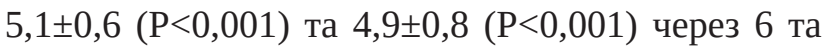
12 місяців відповідно. В другій групі хворих виявлено зміни даного показника від рівня $16,2 \pm 8,4$ до $7,2 \pm 1,9$ через 6 місяців $(\mathrm{P}<0,001)$, та $10,4 \pm 1,7$ через 12 місяців $(\mathrm{P}<0,001)$. Міжгрупове порівняння даних дозволило виявити більш суттєве покращення якості життя у хворих, яким виконували хірургічні втручання $(\mathrm{p}<0,01)$.

Впродовж останніх років як першочергові лікувальні заходи при ГЕРХ прийнято призначати консервативне лікування, що включає ІПП. Виявлено, що для купірування позастравохідних проявів ГЕРХ необхідне застосування більш високих доз ІПП впродовж більш тривалого часу, ніж при типових проявах захворювання [5]. При наявності патологічних гастроезофагеальних рефлюксів застосування ІПП не дозволяє контролювати пошкоджувальний виплив пепсину, трипсину, бактерій та їхніх продуктів на слизову стравоходу, а підвищення $\mathrm{pH}$ вмісту шлунка може потенціювати їхню пошкоджувальну дію [1]. Дія вищенаведених факторів може провокувати виникнення позастравохідних проявів ГЕРХ, що не тільки нечутливі до терапії ІПП, а й прогресують при іiї застосуванні $[1,5]$. Так, виявлено, що у пацієнтів, яким виконували консервативну терапію ГЕРХ, як типова, так і респіраторна симптоматика максимально регресувала через 6 місяців після лікування, проте через 12 місяців спостерігали тенденцію до ії̈ погіршення. Пацієнти вказували на суттєве покращення загального самопочуття, зменшення або нівелювання симптомів ГЕРХ після початку консервативної терапії, однак після припинення приймання препаратів симптоматика відновлювалась. Цікавим виявився факт, що у частини хворих із часом ефект від приймання препаратів зменшувався, аж до повної відсутності.

Таблиця 1. Динаміка клінічних показників

\begin{tabular}{|c|c|c|c|c|}
\hline Показник & Момент огляду & Перша група, n=41 & Друга група, n=25 & $\mathrm{p}$ \\
\hline \multirow{3}{*}{ Кількість нападів кашлю } & до лікування & $14,3 \pm 4,4(7-21)$ & $14,1 \pm 2,5$ (9-19) & 0,8384 \\
\hline & через 6 міс. & $2,3 \pm 1,8(0-5)$ & $4,4 \pm 3,4(0-16)$ & 0,0020 \\
\hline & через 12 міс. & $2,2 \pm 1,7(0-6)$ & $9,7 \pm 4,8(0-17)$ & $<0,0001$ \\
\hline \multirow{3}{*}{$\begin{array}{l}\text { Інтенсивність кашлю за } \\
\text { ВАШ }\end{array}$} & до лікування & $4,3 \pm 2,6(2-6)$ & $3,9 \pm 1,9(2-7)$ & 0,5129 \\
\hline & через 6 міс. & $1,6 \pm 0,8(0-2)$ & $2,3 \pm 1,0(0-5)$ & 0,0030 \\
\hline & через 12 міс. & $1,1 \pm 0,7(0-2)$ & $3,1 \pm 1,2(0-7)$ & $<0,001$ \\
\hline \multirow[t]{3}{*}{ Індекс DeMeester } & до лікування & $74,2 \pm 15,1$ & $71,6 \pm 19,0$ & 0,5461 \\
\hline & через 6 міс. & $15,9 \pm 8,0$ & $21,9 \pm 13,1$ & 0,0263 \\
\hline & через 12 міс. & $12,7 \pm 4,3$ & $42,2 \pm 9,4$ & $<0,0001$ \\
\hline \multirow{3}{*}{$\begin{array}{l}\text { Індекс симптому } \\
\text { рефлюксного кашлю }\end{array}$} & до лікування & $66,1 \pm 10,9$ & $62,3 \pm 8,1$ & 0,1424 \\
\hline & через 6 міс. & $11,5 \pm 4,4$ & $21,8 \pm 6,4$ & $<0,0001$ \\
\hline & через 12 міс. & $10,7 \pm 3,8$ & $49,5 \pm 5,7$ & $<0,0001$ \\
\hline
\end{tabular}


Консервативна антирефлюксна терапія ГЕРХ $\epsilon$ симптоматичною, спрямована на зниження $\mathrm{pH}$ шлункового вмісту та не здатна вплинути на механізм виникнення ГЕРХ. Найбільш поширеною причиною виникнення ГЕРХ є ГСОД [11]. При наявності у пацієнта такого патологічного дефекту виникає топографо-анатомічна нестабільність та періодичне зміщення шлунково-стравохідного переходу в середостіння, що, в свою чергу, призводить до порушень антирефлюксного бар'єра [12]. Так, впадання стравоходу в шлунок через згладження кута Нis призводить до порушення функції складки Губарєва і розетки слизової оболонки кардії. Періодична дислокація фундального відділу шлунка в грудну порожнину провокує розширення грижового дефекту, що знижується констрикторну дію ніжок діафрагми. В зв'язку з переміщенням у грудну порожнину абдомінального відділу стравоходу виникає дезорганізація в його моториці та порушення функціонування нижнього стравохідного сфінктера $[11,12]$. Відновлення антирефлюксного бар'єра шляхом виконання лапароскопічної фундоплікації здатне усунути гастроезофагеальний рефлюкс на відміну від консервативної терапії, яка лише змінює хімічні властивості рефлюксанту. Даний факт підтверджено у проведених нами дослідженнях, де виявлено, що лапароскопічні фуноплікації значно ефективніші від медикаментозного лікування як в плані купі-

\section{СПИСОК ЛІТЕРАТУРИ}

1. Pearson J. P. Review article: reflux and its consequences the laryngeal, pulmonary and oesophageal manifestations. Conference held in conjunction with the 9th International Symposium on Human Pepsin (ISHP) Kingston-upon-Hull, UK, 21-23 April 2010 / J. P. Pearson, S. Parikh, R. C. Orlando [et al.] // Aliment Pharmacol. Ther. - 2011. - Vol. 33 (1). - P. 1-71.

2. Овсянников Е. С. Гастроэзофагеальная рефлюксная болезнь как причина хронического кашля / Е. С. Овсянников, Г. Г. Семенкова // Cosilium Medicum. - 2004. - 6 - № 10 [Електронний ресурс]. - Режим доступу : www.gastroscan.ru

3. Ryan Madanick D. Management of GERD-related chronic cough / D. Ryan Madanick // Gastroenterol. Hepatol. (N Y). 2013. - Vol. 9 (5). - P. 311-313.

4. Kollarik M. Cough and gastroesophageal reflux: Insights from animal models / M. Kollarik, M. Brozmanova // Pulm. Pharmacol. Ther. - 2009. - Vol. 22 (2). - P. 130-134.

5. Medical treatment of gastro-oesophageal reflux disease / F. De Giorgi, M. F. Savarese, E. Atteo [et al.] // Acta. Otorhinolaryngol. Ital. - 2006. - Vol. 26 (5). - P. 276-280.

6. Effects of cruroraphy and laparoscopic Nissen fundoplication procedures on pulmonary function tests in gastroesophageal reflux patients / I. Ozaydin, Ali Nihat Annakkaya, C. Ozaydin [et al.] // Int. J. Clin. Exp. Med. - 2014. - Vol. 7 (2). - P. 431-434. 7. Грубник В. В. Критические аспекты лапароскопической хирургии гастроэзофагеальной рефлюксной болезни и грыж пищеводного отверстия диафрагмы / В. В. Грубник, А. В. Малиновский. - Одеса : ВМВ-типография, 2015. - 106 с. рування типової $(\mathrm{p}<0,01)$, так і атипової $(\mathrm{p}<0,0001)$ симптоматики ГЕРХ.

3 літературних джерел відомо, що основним недоліком хірургічного лікування $€$ відносно висока частота рецидиву ГСОД, що може сягати близько 30-50 \%, особливо при великих розмірах грижового дефекту $[7,13]$. Наслідком такого патологічного стану є відновлення симптоматики ГЕРХ та необхідність виконання повторного хірургічного втручання. Операційні втручання при рецидиві ГСОД є технічно складнішими для хірурга та гірше переносяться пацієнтом психологічно. Результати наших досліджень збігаються з результатами інших науковців [14] відносно того, що використання сітчатих імплантантів дозволяє суттєво знизити частоту рецидиву ГСОД, а якість життя пацієнтів, яким здійснювали пластику ГСОД сітчатим імплантатом, не відрізняється від такої, як у оперованих хворих із малими ГСОД.

Висновки. 1. Лапароскопічні фундоплікацій за Ніссеном з пластикою ГСОД ефективний та безпечний метод лікування як типової, так і респіраторної симптоматики ГЕРХ.

2. Виконання лапароскопічних фундоплікацій в поєднанні з пластикою ГСОД достовірно ефективніше від консервативної терапії, відносно покращення якості життя та регресу симптоматики у хворих і позастравохідними респіраторними проявами ГЕРХ.

8. Ambulatory 24 hour esophageal $\mathrm{pH}$ monitoring. Reproducibility and variability of $\mathrm{pH}$ parameters / G. J. Wiener, T. M. Morgan, J. B. Copper [et al.] // Dig. Dis. Sci. - 1988. Vol. 33 (9). - P. 1127-1133

9. Velanovich V. Comparison of generic (SF-36) vs. Diseasespecific (GERD-HRQL) quality-of-life scales for gastroesophageal reflux disease / V. Velanovich // J. of Gastrointestinal Surgery. - 1998. - Vol. 2 (2). - P. 141-145

10. Грубник В. В. Использование самофиксирующих сеток Progrip при лапароскопической пластике грыж пищеводного отверстия диафрагмы / В. В. Грубник, А. В. Малиновский, В. В. Грубник // Укр. журн. малоінвазив. та ендоскоп. хірургiï. $-2016 .-20$ ( 3). - C. 38

11. Oshima T. Pathogenesis of gastro-esophageal reflux disease / T. Oshima, H. Miwa // Nihon Rinsho. - 2007. - Vol. 65 (5). P. 797-801.

12. Pathophysiology of gastro-esophageal reflux disease / F. De Giorgi, M. Palmiero, I. Esposito [et al.] // Acta Otorhinolaryngol. Ital. - 2006. - Vol. 26 (5). - P. 241-246.

13. Frantzides C. T. Aprospective, randomized trial of laparoscopic polytetrafluoroethylene (PTFE) patch repair vs simple cruroplasty for large hiatal hernia / C. T. Frantzides, A. K. Madan, M. A. Carlson // Stavropoulos Archives of Surgery. - 2002. - Vol. 137 (6). - P. 649-652.

14. Furnee E. Mesh in laparoscopic large hiatal hernia repair: a systematic review of the literature / E. Furnee, E. Hazebroek // Surgical Endoscopy. - 2013. - Vol. 27 (11). - P. 3998-4008. 


\section{REFERENCES}

1. Pearson, J.P., Parikh, S., Orlando, R.C., Johnston, N., Allen, J., Tinling, S.P., \& Johnston, N. (2011). Review article: reflux and its consequences - the laryngeal, pulmonary and oesophageal manifestations. Aliment Pharmacol. Ther; Conference held in conjunction with the 9th International Symposium on Human Pepsin (ISHP); Kingston-upon-Hull, UK. 21-23 April 2010. Aliment. Pharmacol. Ther., 33, 1-71.

2. Ovsiannikov, E.S., \& Semenkova, G.G. (2004). Gastroezofagealnaya reflyuksnaya bolezn kak prichina khronicheskogo kashlya [Gastroesophageal reflux disease as the cause of chronic cough]. Cosilium Medicum, 6 [in Russian].

3. Ryan, D. Madanick (2013). Management of GERD-related chronic cough. Gastroenterol. Hepatol., 9 (5), 311-313.

4. Kollarik, M., \& Brozmanova, M. (2009). Cough and gastroesophageal reflux: insights from animal models. Pulm. Pharmacol. Ther., 22 (2), 130-134.

5. De Giorgi, F., Savarese, M.F., Atteo, E., Leone, C.A., \& Cuomo, R. (2006). Medical treatment of gastro-oesophageal reflux disease. Acta Otorhinolaryngol. Ital., 26 (5), 276-280.

6. Ozaydin, I., Annakkaya Ali Nihat, Ozaydin, C., \& Metin, Aydin (2014). Effects of cruroraphy and laparoscopic Nissen fundoplication procedures on pulmonary function tests in gastroesophageal reflux patients. Int. J. Clin. Exp. Med., 7 (2), 431-434.

7. Grubnik, V.V., \& Malinovskiy, A.V. (2015). Kriticheskie aspekty laparoskopicheskoy khirurgii gastroezofagelnoy reflyuksnoy bolezni i gryzh pishchevodnogo otverstiya diafragmy [Critical aspects of laparoscopic surgery of gastroesophageal reflux disease and esophageal hiatal hernia]. Odessa: VMF- tipografiya [in Russian].

8. Wiener, G.J., Morgan, T.M., Copper, J.B., Castell, D.O., Sinclair, J.W., \& Richter, J.E. (1988). Ambulatory 24 hour esophageal $\mathrm{pH}$ monitoring. Reproducibility and variability of $\mathrm{pH}$ parameters. Dig. Dis. Sci., 33 (9), 1127-1133.

9. Velanovich, V. (1998). Comparison of generic (SF-36) vs. Diseasespecific (GERD-HRQL) quality-of-life scales for gastroesophageal reflux disease. J. of Gastrointestinal Surgery, 2 (2), 141-145.

10. Grubnik, V.V., Malinovskiy, A.V., \& Grubnik, V.V. (2016). Ispolzovanie samofiksiruyushchikh setok Progrip pri laparoskopicheskoy plastike gryzh pishchevodnogo otverstiya diafragmy [The use of self-gripping Progrip mesh during laparoscopic hiatal hernia repair]. Ukr. zhurn. maloinvazyv. ta endoskop. Khirurhii - Ukrainian Journal of Small-invasive and Endoscopic Surgery, 20 (3), 38 [in Russian].

11. Oshima T., \& Miwa H. (2007). Pathogenesis of gastroesophageal reflux disease. Nihon Rinsho, 65 (5), 797-801.

12. De Giorgi, F., Palmiero, M., Esposito, I., Mosca, F., \& Cuomo, R. (2006). Pathophysiology of gastro-esophageal reflux disease. Acta. Otorhinolaryngol. Ital., 26 (5), 241-246. 13. Frantzides, C.T., Madan, A.K., \& Carlson, M.A. (2002) Aprospective, randomized trial of laparoscopic polytetrafluoroethylene (PTFE) patch repair vs simple cruroplasty for large hiatal hernia. Stavropoulos Archives of Surgery, 137 (6), 649-652.

14. Furnee, E., \& Hazebroek, E. (2013). Mesh in laparoscopic large hiatal hernia repair: a systematic review of the literature. Surgical Endoscopy, 27 (11), 3998-4008.

Отримано 13.04.2017

M. R. PARANYAK, V. V. GRUBNIK

Odessa National Medical University

\title{
THE EFFECTIVENESS OF SURGICAL TREATMENT OF PATIENTS WITH RESPIRATORY SYMPTOMS OF GASTROESOPHAGEAL REFLUX DISEASE
}

\begin{abstract}
The aim of the study: comparison of the effectiveness of conservative therapy and surgical treatment of patients with respiratory manifestations of gastroesophageal reflux disease and hiatal hernia.

Materials and Methods. 41 patients underwent laparoscopic Nissen fundoplication and 25 patients - conservative therapy of gastroesophageal reflux disease. The results of the treatment were assessed using 24-hour $\mathrm{pH}$-monitoring of the esophagus and the GERDHRQL quality of life questionnaire. Likert heartburn intensity, intensity of coughing attacks according to 10-point visual analogue scale, quantitative index of coughing attacks for one day, symptom index of reflux cough were then made.

Results and Discussion. We established significantly better results $(\mathrm{p}<0.001)$ relative decrease in the frequency and intensity of cough in patients who performed laparoscopic fundoplication. Regression typical symptoms was also better $(\mathrm{p}<0.001)$ in patients undergoing surgery.
\end{abstract}

Key words: gastroesophageal reflux disease; laparoscopic fundoplication; extraesophageal manifestations; cough. 
Н. Р. ПАРАНЯК, ВИКТ. ВЛ. ГРУБНИК

Одесский национальный медицинский университет

\title{
УФФЕКТИВНОСТЬ ХИРУРГИЧЕСКОГО ЛЕЧЕНИЯ БОЛЬНЫХ С РЕСПИРАТОРНЫМИ ПРОЯВЛЕНИЯМИ ГАСТРОЭЗОФАГЕАЛЬНОЙ РЕФ.ЛЮКСНОЙ БОЛЕЗНИ
}

\begin{abstract}
Цель исследования: сравнение эффективности консервативной терапии и хирургического лечения пациентов с респираторными проявлениями гастроэзофагеальной рефлюксной болезни и грыжами пищеводного отверстия диафрагмы. Материалы и методы. 41 пациенту было выполнено лапароскопические фундопликации по Ниссену и 25 пациентам проводилась консервативная терапия гастроэзофагеальной рефлюксной болезни. Результаты лечения были оценены с помощью круглосуточного pH-мониторинга пищевода и опросника качества жизни GERD-HRQL. Также выполняли определения интенсивности изжоги по шкале Likert, интенсивности приступов кашля по данным 10-бальной визуальной аналоговой шкалы, количественного показателя приступов кашля в течение суток, индекса симптома рефлюксного кашля.

Результаты исследований и их обсуждение. Установлено достоверно лучший результат (р <0,001) относительно уменьшения частоты и интенсивности кашля у больных, которым выполнялись лапароскопические фундопликации. Регресс типичной симптоматики также был лучшим (р <0,001) у больных, которым проводились хирургические вмешательства.
\end{abstract}

Ключевые слова: гастроэзофагеальная рефлюксная болезнь; лапароскопическая фундопликация; внепищеводные проявления; кашель. 